\title{
Microplastics in Agricultural Soils: A Case Study in Cultivation of Watermelons and Canning Tomatoes
}

\author{
Ekavi A. Isari ${ }^{1}$, Dimitrios Papaioannou ${ }^{1}$, Ioannis K. Kalavrouziotis ${ }^{1}$ and Hrissi K. Karapanagioti ${ }^{2, *(D)}$ \\ 1 School of Science and Technology, Hellenic Open University, Parodos Aristotelous 18, 26335 Patras, Greece; \\ ekavi.isari@eap.gr (E.A.I.); dimpapas1@yahoo.gr (D.P.); ikalabro@eap.gr (I.K.K.) \\ 2 Department of Chemistry, University of Patras, 26504 Patras, Greece \\ * Correspondence: karapanagioti@upatras.gr
}

Citation: Isari, E.A.; Papaioannou, D.; Kalavrouziotis, I.K.;

Karapanagioti, H.K. Microplastics in Agricultural Soils: A Case Study in Cultivation of Watermelons and Canning Tomatoes. Water 2021, 13, 2168. https://doi.org/10.3390/ w13162168

Academic Editor: Luiza Campos

Received: 30 June 2021

Accepted: 4 August 2021

Published: 7 August 2021

Publisher's Note: MDPI stays neutral with regard to jurisdictional claims in published maps and institutional affiliations.

Copyright: (c) 2021 by the authors. Licensee MDPI, Basel, Switzerland. This article is an open access article distributed under the terms and conditions of the Creative Commons Attribution (CC BY) license (https:// creativecommons.org/licenses/by/ $4.0 /)$.

\begin{abstract}
Thirty soil samples were collected from fields that have been used for cultivating watermelons and canning tomatoes for over 10 years. The microplastics (MPs) within these samples were separated with a density floatation method and the use of sieves and filters. The microplastics found were black and originated from the black agricultural mulch film (BMF) used in these cultivations. ATR-FTIR spectroscopy revealed that these microplastics are of the same material as the virgin BMF and as a virgin polyethylene film used as blank. SEM images showed that used BMF and MPs found in soil were oxidized by their exposure to sunlight and create fibrous edges that lead to the creation of smaller size MPs. The number of MPs found in fields with watermelon (301 \pm 140 items kg-1) were more than four times higher than in fields with canning tomatoes $\left(69 \pm 38\right.$ items $\left.\mathrm{kg}^{-1}\right)$ due to the double planting each year and to the second planting last year being closer to the sampling episode. All the sample sites were collected from agricultural fields away from the industrial area; therefore, these results prove that agricultural activities might have caused contamination of soils with MPs. This is corroborated even more by the fact that no MPs were found in five extra samples that were taken from uncultivated areas as blanks.
\end{abstract}

Keywords: soil pollution; microplastics; environment; agricultural fields

\section{Introduction}

In the last decades, microplastics (MPs) have become a global environmental problem. MP pollution has many potential sources such as industry, agriculture, landfill, wastewater treatment plants, household waste, tires, synthetic textiles, and packaging materials.

The knowledge about the ecological impacts, on the terrestrial environment and especially in agro-ecosystems, of the plastic pollution and the potential consequences of MPs in agriculture (sustainability and food safety) is limited [1]. MPs are emerging contaminants of increasing concern [2] and several potential sources of MPs in agricultural soils have been identified [3]. However, only a few recent studies have examined the pollution levels of MPs in the agricultural soils.

Referring to the sources of MPs in agricultural soils, it must be noted that several MPs are added to agricultural soils by many farmer activities. The most common applications of polyethylene (PE) plastics in agriculture are the following [4]: Greenhouses, as permanent cover materials; low tunnels, to cover crops such as melons, watermelons, strawberries, etc., for a short period; mulching films to control the soil's temperature and moisture, to prevent irrigation water from evaporating and for weed growth deceleration [5]; plastic irrigation tubes.

In addition, large plastic items which are present in soil, gradually become small fragments and MP particles, due to various environmental weathering processes, mechanical breakdown, decomposition, and photo-degradation [6]. Working in soil conditions with polyethylene plastic bags, Orhan et al. [7] detected microplastic pieces but did not detect significant surface degradation of the synthetic polymer. 
However, even if plastics are important for horticulture, to the best of our knowledge, no detailed studies for the quantification of plastics use in the agricultural sector have been carried out. On the contrary, several publications were made concerning the use of plastics in European agriculture with special focus the protected agriculture which is the most dynamic sector of modern agriculture [8].

To investigate and evaluate environmental risk of MPs contamination requires a method for extracting MP particles from environmental samples. MPs are defined as the plastic items which measure less than $5 \mathrm{~mm}$ in their longest dimension [9]. MPs, as part of large plastics items, when exposed to environmental conditions that involve physical, biological, and chemical processes, follow a further fragmentation, and become nanoplastics.

Soil is a heterogeneous solid and the separation of MPs is difficult. Finding a method for soil dispersion without the destruction or fragmentation of MPs is an important purpose for the MPs study. Many procedures have been applied to extract the MPs from soil. The most easily, low cost and the simplest method for reproducible easier method is the floating extraction. One of the objectives of the present work is to apply an MPs extraction technique on soils cultivating canning tomatoes and watermelons, to recognize and quantify the MPs. In the present study, only the MPs coming from the black PE cover will be counted that are relevant to agricultural practices of the sites tested.

\section{Materials and Methods}

\subsection{Soil Samples Collection}

Ten soil samples were collected from agricultural land located in Ilia County of the Western Greece Region. Agricultural areas have been cultivated with canning tomatoes and watermelons for at least the last ten years. Surface soils were collected from the top layer (0-30 cm depth) using a stainless-steel shovel, preventing sample contamination by plastics. A quantity of soil (about $1.5 \mathrm{~kg}$ ) was collected from three different sampling locations in each cultivated field. The soil samples were collected from five different cultivated fields of watermelon (WSS_1,WSS_2, WSS_3, WSS_4,WSS_5) and five of canning tomato (TSS_1, TSS_2, TSS_3, TSS_4, TSS_5). The soil samples were placed in covered aluminum containers and were transferred to the laboratory. After the samples were air-dried, they were sieved through a $5 \mathrm{~mm}$ stainless steel mesh. Furthermore, five soil samples were collected from non-cultivated lands as blanks, using the same soil sampling procedure, to compare the results of MPs items with those of the cultivated sites.

\subsection{Materials}

Sodium chloride $(\mathrm{NaCl})$ was obtained from Merk (Lot K34243404 504) without further purification. The saturated solutions of $\mathrm{NaCl}$, for the density separation protocol of the MPs, were prepared with purified water (Milli-Q Academic).

Hydrogen peroxide $\left(\mathrm{H}_{2} \mathrm{O}_{2}\right) 30 \%$ from PENTA, applied for the destruction of the soil organic matter in MPs.

For the identification of the MPs, via comparative study, a virgin black agricultural mulch film (BMF) with $0.92 \mathrm{~g} \mathrm{~cm}^{-3}$ density from agricultural store and PE film from Merck were obtained. In some of the soil samples, large pieces $(>5 \mathrm{~mm})$ of used BMF were found and were used to compare with the virgin BMF bought from the store.

\subsection{Floatation with $\mathrm{NaCl}$ Solution}

A density separation protocol has been developed due to MPs relatively light density. Saturated sodium chloride $(\mathrm{NaCl})$ solution $\left(1.18 \mathrm{~g} \mathrm{~cm}^{-3}\right)$ was used to isolate MPs from the soil matrix, through floatation. Each soil sample of $150 \mathrm{~g}$ was decanted into the high-density solution $(600 \mathrm{~mL})$. The suspension stirred at $200 \mathrm{rpm}$ for $5 \mathrm{~min}$ and stood at rest for $2 \mathrm{~h}$. MP particles were floated on the surface of the suspension and the denser soil materials remained at the bottom of the solution gradient. The supernatant was filtered through a $500 \mu \mathrm{m}$ stainless steel sieve and MPs larger than $500 \mu \mathrm{m}$ were collected. The remaining filtrate was then filtered by a $20 \mu \mathrm{m}$ paper filter and MPs larger than $20 \mu \mathrm{m}$ were collected. 
The same procedure was carried out at least twice for each sample until no materials were seen floating in the supernatant. Three replicates for each sample were carried out. The collected MPs were counted by hand. An additive oxidation digestion step required for the removal of the remained organic matter on the filter and the MPs. The two fractions of the isolated MPs $(5 \mathrm{~mm}>\mathrm{MPs}>500 \mu \mathrm{m}$ and $500>$ MPs $>20 \mu \mathrm{m})$ were oxidized by $30 \% \mathrm{H}_{2} \mathrm{O}_{2}$ for 2 days, at $70{ }^{\circ} \mathrm{C}$ in a petri dish, to be separated by organic matter particles with similar density, that remained after filtration (Figure 1).

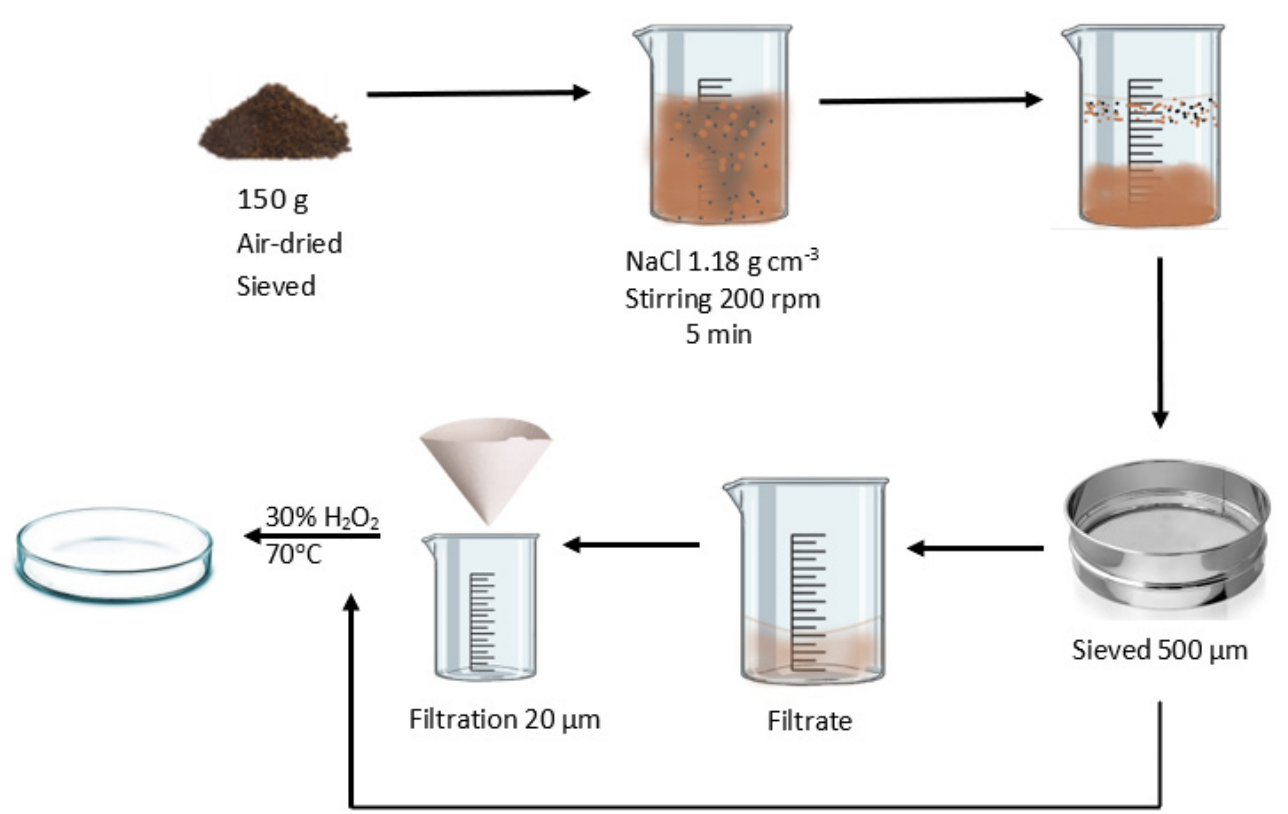

Figure 1. Schematic representation of the MPs extraction procedure by $\mathrm{NaCl}$ floatation.

\subsection{Instruments}

Initially, the isolated floated items of the density extraction procedure, are identified by Stereo microscope-MSL4000-Kruss at 20× for the pre-screening of any observed particles that visually resembled MPs. Identification of the origin and the type of the plastic material that was broken to MPs was performed by attenuated total reflectance-Fourier transform infrared spectroscopy (ATR-FTIR) (Spectrum 100, PerkinElmer Inc., Shelton, CT, USA). ATR-FTIR was used in transmittance mode, with spectral range of $4000-650 \mathrm{~cm}^{-1}$, sample scan time $20 \mathrm{~s}$ and resolution $4 \mathrm{~cm}^{-1}$. All spectra were processed via the Spectrum software (Perkin Elmer). Scanning electron microscope (SEM) imaging confirm the type of the MPs and reveal the morphology of the unused and used BMFs and their fragments. The samples were rinsed gently with sterile water, dehydrated with a graded ethanol series, and air-dried. Subsequently, samples were sputter coated with $5 \mathrm{~nm}$ of platinum and visualized with a JEOL 6300 scanning electron microscope.

\section{Results and Discussion}

\subsection{Microplastic Identification and Characterization}

In the first step of the MPs identification during their visual observation by the stereo microscope at 20× magnification, MPs were successfully identified, classified based on their size, and counted. The results are presented in Table 1. All the extracted plastic fragments were black with strong asymmetry and a lacy finish, indicating that their common source was the black plastic mulch film (BMF) (Figures 2 and 3). 
Table 1. Microplastics (MPs) abundance in cultivations soil samples.

\begin{tabular}{|c|c|c|c|c|c|c|c|c|c|c|c|}
\hline \multicolumn{12}{|c|}{ MPs (Items kg ${ }^{-1}$ ) } \\
\hline & \multirow{2}{*}{ Sample } & \multicolumn{3}{|c|}{3 Soil Replicates } & \multicolumn{3}{|c|}{3 Soil Replicates } & \multirow{2}{*}{\multicolumn{3}{|c|}{3 Soil Replicates Total }} & \multirow{2}{*}{$\begin{array}{c}\text { Mean } \\
\text { Value } \pm \text { STD }\end{array}$} \\
\hline & & \multicolumn{3}{|c|}{$(20 \mu \mathrm{m}<\mathrm{MPs}<500 \mu \mathrm{m})$} & \multicolumn{3}{|c|}{$(500 \mu \mathrm{m} \leq \mathrm{MPs}<5 \mathrm{~mm})$} & & & & \\
\hline \multirow{5}{*}{ WSS } & WSS_1 & 14 & 20 & 13 & 173 & 253 & 187 & 187 & 273 & 200 & $220 \pm 47$ \\
\hline & WSS_2 & 13 & 27 & 27 & 287 & 333 & 320 & 300 & 360 & 347 & $336 \pm 32$ \\
\hline & WSS_3 & 7 & 6 & 20 & 160 & 247 & 127 & 167 & 253 & 147 & $189 \pm 57$ \\
\hline & WSS_4 & 22 & 15 & 18 & 525 & 545 & 542 & 547 & 560 & 560 & $556 \pm 8$ \\
\hline & WSS_5 & 20 & 7 & 7 & 207 & 180 & 200 & 227 & 187 & 207 & $207 \pm 20$ \\
\hline \multirow{5}{*}{ TSS } & TSS_1 & 27 & 40 & 40 & 20 & 13 & 13 & 47 & 53 & 53 & $51 \pm 4$ \\
\hline & TSS_2 & 33 & 20 & 27 & 27 & 20 & 33 & 60 & 40 & 60 & $53 \pm 12$ \\
\hline & TSS_3 & 64 & 67 & 76 & 93 & 53 & 67 & 157 & 120 & 143 & $140 \pm 19$ \\
\hline & TSS_4 & 53 & 0 & 14 & 20 & 60 & 33 & 73 & 60 & 47 & $60 \pm 13$ \\
\hline & TSS_5 & 13 & 7 & 13 & 47 & 13 & 27 & 60 & 20 & 40 & $40 \pm 20$ \\
\hline
\end{tabular}
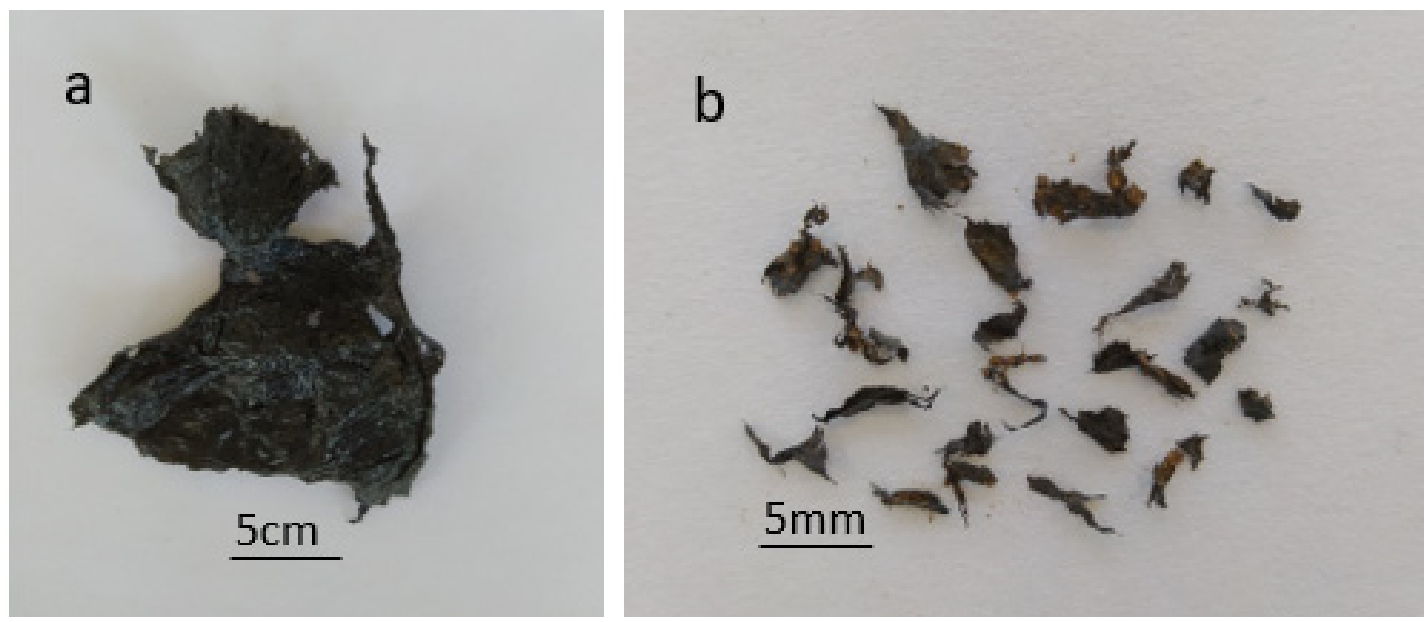

Figure 2. Pictures of used black plastic mulch (a) and microplastics (b) detected on the investigated agricultural areas.

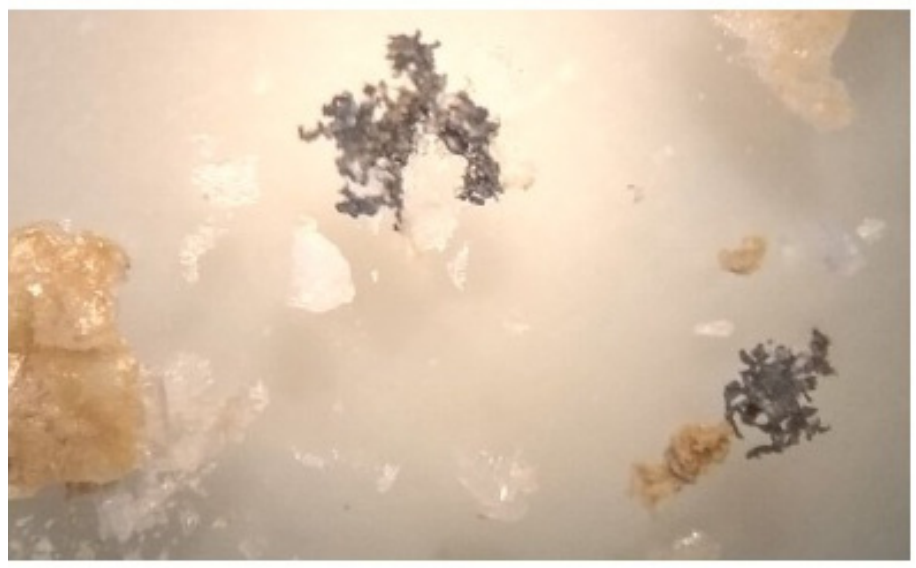

Figure 3. MPs shape under stereoscope with $20 \times$ magnification.

To confirm the polymer type of MPs, a comparative FTIR-ATR spectroscopic analysis was performed, among blank PE, unused BMF, used BMF, and MP items (Figure 4). The characteristic bands of the PE can be identified for the spectra of the BMF and the MPs. The bands 2919 and $2843 \mathrm{~cm}^{-1}$ have been assigned to $\mathrm{C}-\mathrm{H}$ stretch vibrations; the band at $1460 \mathrm{~cm}^{-1}$ represents $\mathrm{CH}_{2}$ bending vibrations and the $715 \mathrm{~cm}^{-1}$ could be considered as a methyl rock band [10,11]. At the fingerprint area, the MP sample has a band at $998 \mathrm{~cm}^{-1}$ 
which can be attributed to the O-C group [12,13]. The particular band could be evidence of photooxidation of the used BMF and its fragments (MPs in Figure 4).

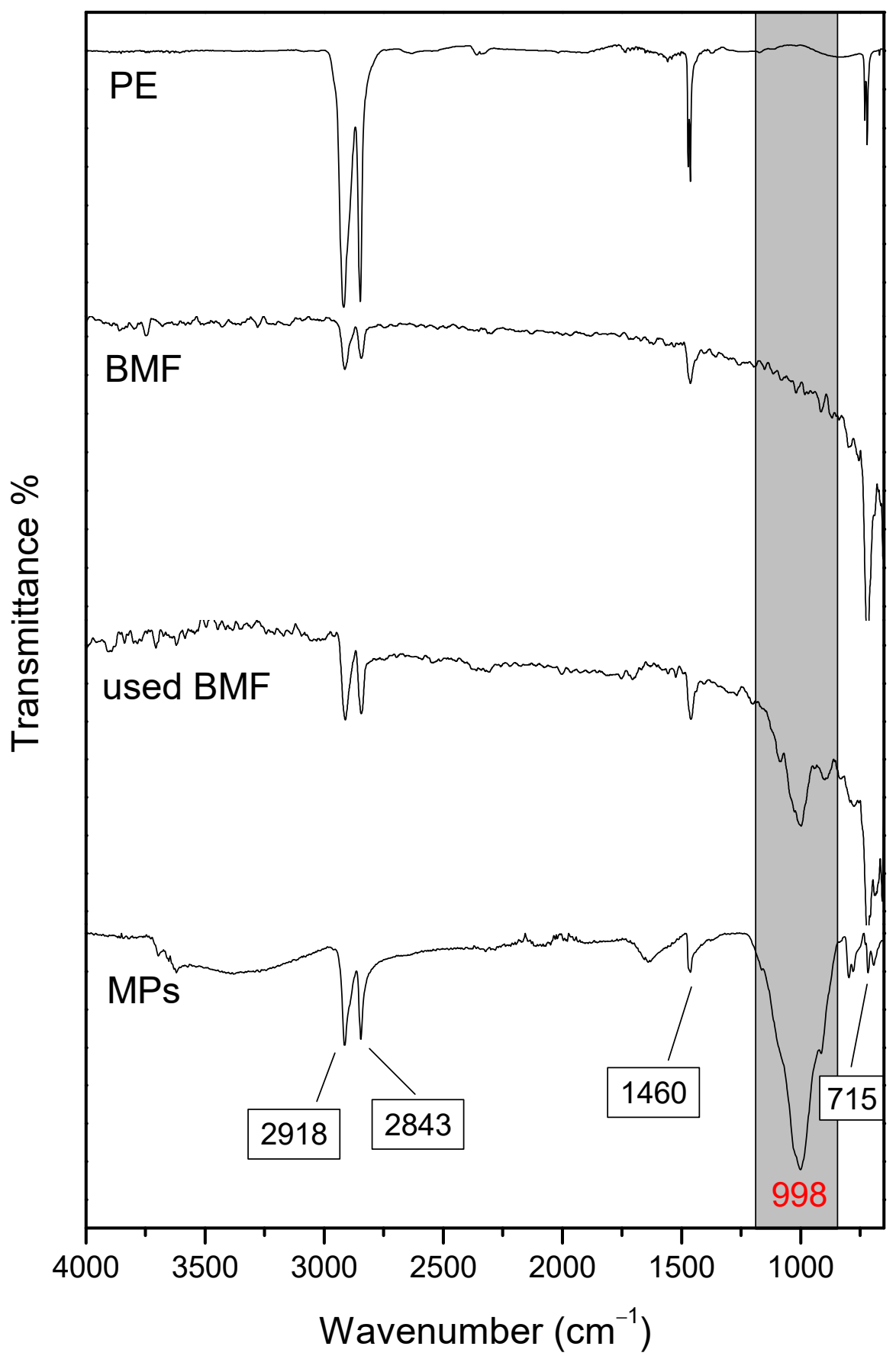

Figure 4. ATR-FTIR spectra of PE, BMF, used BMF, and the soil extracted MPs.

\subsection{Microplastic Origin and Formation}

In addition to ATR-FTIR spectroscopy, the SEM imaging technique shows the morphological differences between the MPs samples and the virgin and used BMF (Figure 5). The images reveal changes in the surface roughness of BMF material due to its degradation over time. The BMF is fragmented by its exposure to UV radiation of the sunlight [14] and the mechanical stress from the agricultural activities as indicated by the SEM images of the used BMF and the MP sample showing cracks and fibrous edges in comparison with the smooth surface of the virgin BMF. Similar holes were observed in PE plastic bag films 
found on beaches in Tziourrou et al. [11]. In that study, the edges can be observed only in the macroscopic pictures, and they are indeed fibrous as well. There is no doubt that the MPs observed in the present study originate from the BMF used for cultivation of the watermelon and canning tomatoes. They are similar both in colour and in the shape of the edges.

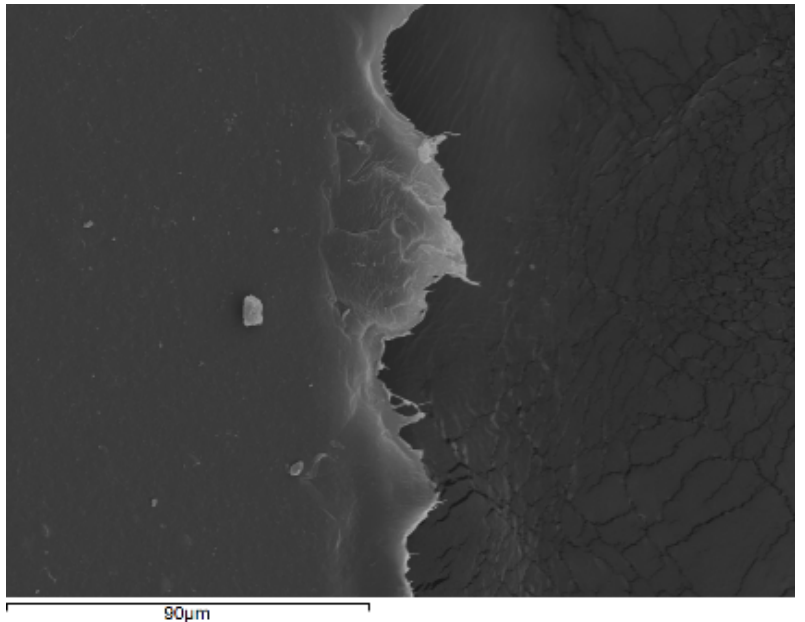

(a)

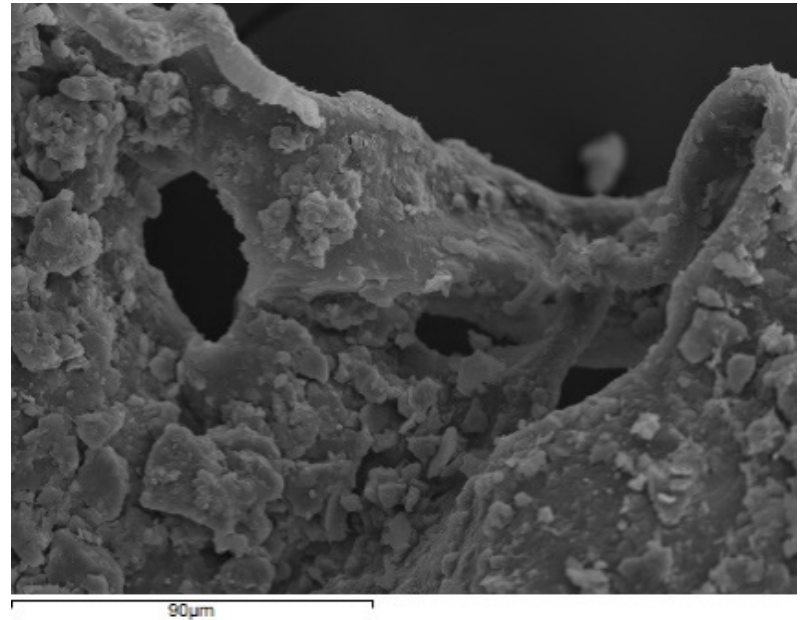

(b)

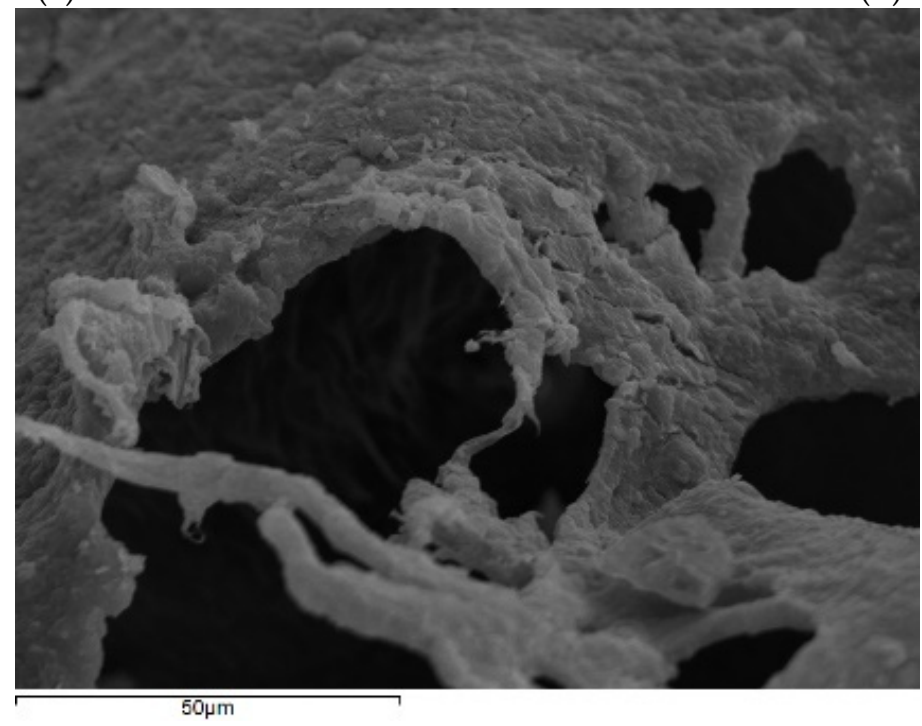

(c)

Figure 5. SEM images of (a) virgin BMF, (b) used BMF, and (c) MP sample.

\subsection{Microplastic Abundance}

In the present study, no black MPs were found in the soil samples of the uncultivated areas. The MPs abundance varied from $189 \pm 57$ to $556 \pm 8$ with an average of $301 \pm 140$ items kg-1 for the WSS and $40 \pm 20$ to $140 \pm 19$ with an average of $69 \pm 38$ items kg-1 for the TSS. The average level of the MPs from the watermelon cultivation is remarkably higher (more than a factor of 4) than the extracted MPs from the tomato cultivated soils. As shown in Figure 6, the soils in which watermelons have been grown contain a larger quantity of MP that also was found with the statistical analysis ( $t$-test) of the measurement means. This difference between the MP of the two cultivations can be explained by the handling and the special requirements of each crop. For example, during the same growing season, two watermelon plantings are grown: the early and the late cultivation. On these fields, the plastic mulches are applied twice per season and the amount of plastic waste in soil is expected to be more. At the same time, with agricultural 
activities to prepare for recultivation, such as soil milling, the initial topsoil is mixed with the deeper soil layers, something that results in reduced small MPs detection (less than $500 \mu \mathrm{m})$.

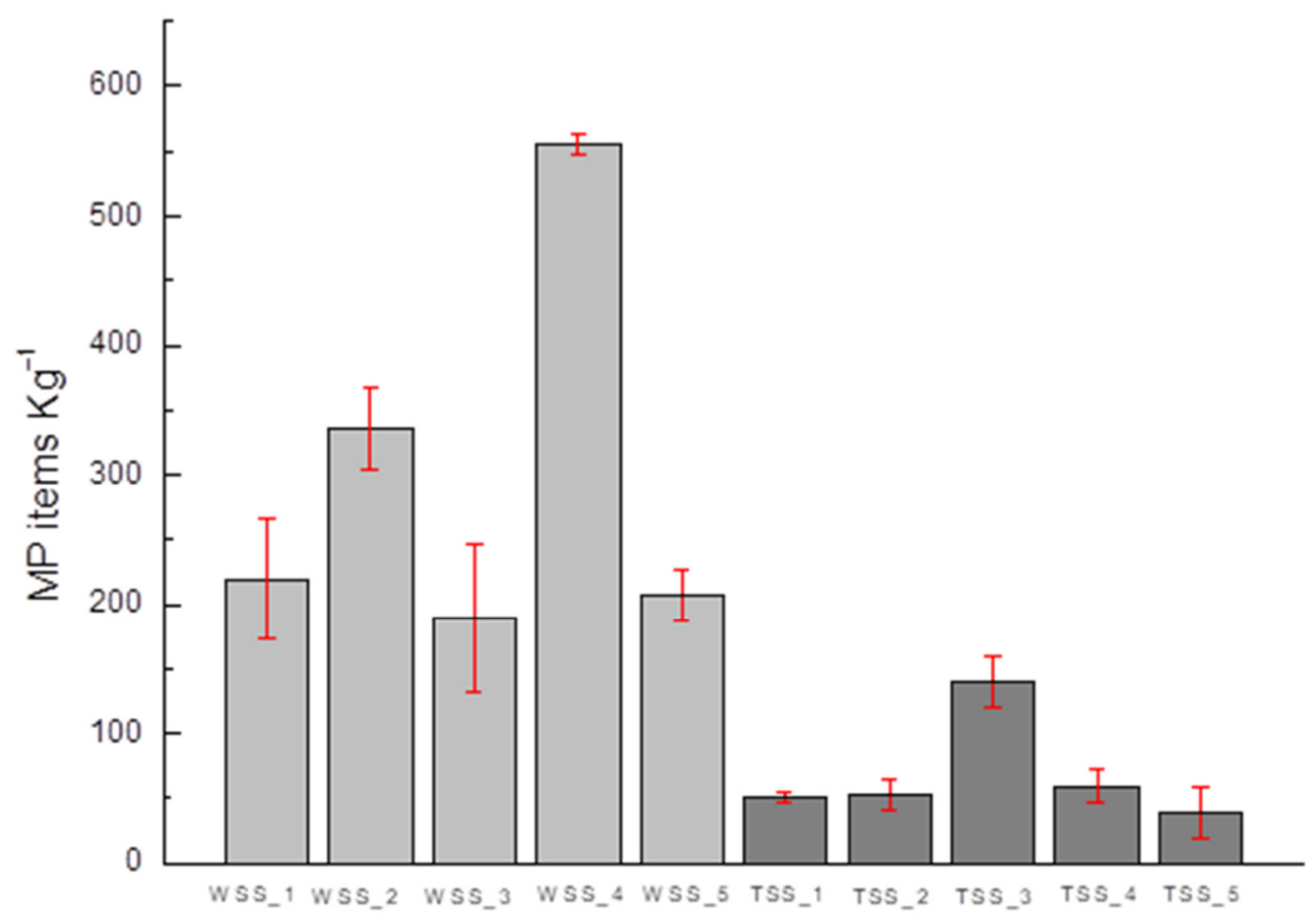

Figure 6. Average microplastic abundance in each field.

In Table 1, the abundance of the two MPs fractions is presented in detail for each soil sample and for each sampling location. For the smaller fraction $(20 \mu \mathrm{m}<$ MPs $<500 \mu \mathrm{m})$, the abundance values in both cultivations are not statistically different (16 \pm 6.8 for WSS versus $33 \pm 22$ items $\mathrm{kg}^{-1}$ for TSS). However, for the larger fraction $(500 \mu \mathrm{m}<\mathrm{MPs}<$ $5 \mathrm{~mm}$ ), the abundance values are 8 times higher for WSS (286 \pm 138 items kg ${ }^{-1}$ ) than for TSS ( $36 \pm 23$ items $\left.\mathrm{kg}^{-1}\right)$. Additionally, one can observe that the abundance values of both size fractions of MPs for TSS are rather similar. This may suggest that there is a residual abundance number left at the different size fractions and the rest is degraded into smaller pieces. In the same line, one can suggest that the WSS fields have larger-sized MPs because of the second planting that was more recent to our sampling episode.

Much higher numbers of MPs can be seen for sample WSS4 compared to the other fields of watermelon cultivation and for sample TSS3 compared to the other fields of tomatoes cultivation. This is a matter of individual practice of each farmer and how carefully the BMFs are collected and disposed after the end of each cultivation period.

\subsection{Discussion}

Plastic mulching is a globally applied agricultural practice for its instant economic benefits [15] and its ability to improve the crop yield by adjusting environmental conditions [16]. In the early 2000s, 0.7 million tonnes of mulch film were used annually worldwide in agriculture, using as basic polymer material polyethylene (PE), polypropylene (PP), polystyrene (PS), polyvinylchloride (PVC), resistant to hydrolytic and enzymatic degradation [17]. However, the common material from which the black mulch film is made is PE [18]. This is also true for the present case study.

At canning tomatoes cultivation, the application of plastic mulching films is a common process. Plastic mulches can be used for one cultivation period. By the end of cultivation, the collection of plastic mulches is required; nevertheless, many conditions and farmers' applications destroy the structure and fragment the films. Since cultivation areas are near 
to the canning industry, the same lands are cultivated with the same process for many years. Cumulatively, by the long-term application of plastics, the plastic items that remain in the soil result in the appearance of MPs in the soil. The canning tomatoes cultivated area in the region of Ilia of western Greece is about $1.000 \mathrm{Ha}$. In watermelon cultivation, similar cultivation techniques have been used with the application of plastic films. Watermelons are another important cultivation in the same region, with a cultivated area of about $2.500 \mathrm{Ha}$. Combining the application of mulching films in agriculture, the cultivation at the same lands for years and the total area of cultivation, the existence of MPs pollutes the agricultural lands.

Significant amounts of MP were found in cultivation soils with canning tomato and watermelon. All the sample sites were collected from agricultural fields away from the industrial area; therefore, these results prove that agricultural activities might have caused contamination of soils with MPs. Examining the effects of plastic mulching application, researchers found that 10 years of mulching left residues at a mass of $50-260 \mathrm{~kg} \mathrm{ha}^{-1}$ [19]. Studies with quantities of MPs in cultivations have been referred by Liu et al. [20] in vegetable fields with $78.00 \pm 12.91$ items $\mathrm{kg}^{-1}$ and Zhang et al. [21] in agricultural fields with $<0.54$ items $\mathrm{kg}^{-1}$.

\section{Conclusions}

Plastics are increasingly being used for agricultural purposes, which increases the possibility of plastic pollution of farmland. The pollution of MPs is worsening globally and the hazards in agricultural soils need attention. Comparing the present experimental results with the referred MPs measurements, the MPs quantity in the studied field showed an evolving environmental problem. Scientific knowledge on MPs demands more concerted efforts in future research, especially to create a standard protocol to isolate, quantify, and characterize MPs from the soil environment.

Author Contributions: Conceptualization, I.K.K., H.K.K., and D.P.; methodology, E.A.I. and D.P.; formal analysis, E.A.I., and D.P.; resources, I.K.K.; data curation, E.A.I., D.P., and H.K.K.; writingoriginal draft preparation, EAI and D.P.; writing-review and editing, H.K.K.; supervision, H.K.K. and I.K.K.; All authors have read and agreed to the published version of the manuscript.

Funding: This research received no external funding.

Informed Consent Statement: Not applicable.

Data Availability Statement: All data are presented in the paper.

Conflicts of Interest: The authors declare no conflict of interest.

\section{References}

1. Bläsing, M.; Amelung, W. Plastics in soil: Analytical methods and possible sources. Sci. Total. Environ. 2018, 612, $422-435$. [CrossRef] [PubMed]

2. He, D.; Luo, Y.; Lu, S.; Liu, M.; Song, Y.; Lei, L. Microplastics in soils: Analytical methods, pollution characteristics and ecological risks. Trends Analyt. Chem. 2018, 109, 163-172. [CrossRef]

3. Papaioannou, D.; Kalavrouziotis, I.K. Possibleeffects on plants due to microplastics in soils from wastewater effluent reuse or sewage sludge application. In Microplastics in Water and Wastewater, 2nd ed.; Karapanagioti, H.K., Kalavrouziotis, I.K., Eds.; International Water Association: London, UK, 2020; pp. 159-175.

4. Jansen, L.; Henskens, M.; Hiemstra, F. Report on Use of Plastics in Agriculture; Schuttelaar \& Partners Edition: Wageningen, The Netherland, 2019; p. 19.

5. Horton, A.A.; Walton, A.; Spurgeon, D.J.; Lahive, E.; Svendsen, C. Microplastics in freshwater and terrestrial environments: Evaluating the current understanding to identify the knowledge gaps and future research priorities. Sci. Total Environ. 2017, 586, 127-141. [CrossRef] [PubMed]

6. Watts, A.J.; Lewis, C.; Goodhead, R.M.; Beckett, S.J; Moger, J.; Tyler, C.R.; Galloway, T.S. Uptake and retention of microplastics by the shore crab Carcinus maenas. Environ. Sci. Technol. 2014, 48, 8823-8830. [CrossRef] [PubMed]

7. Orhan, Y.; Hrenović, J.; Büyükgüngöra, H. Biodegradation of plastic compost bags under controlled soil conditions. Acta Chim. Slov. 2004, 51, 579-588.

8. Scarascia-Mugnozza, G.; Sica, C.; Russo, G. Plastic materials in European agriculture: Actual use and perspectives. J. Agric. Eng. 2011, 42, 15-28. [CrossRef] 
9. GESAMP. Chapter 3.1.2 Defining 'microplastics'. Sources, fate and effects of microplastics in the marine environment: A global assessment. In (IMO/FAO/UNESCO-IOC/UNIDO/WMO/IAEA/UN/UNEP/UNDP Joint Group of Expertson the Scientific Aspects of Marine Environmental Protection (GESAMP)); Kershaw, P.J., Ed.; GESAMP No. 90: London, UK, 2015; p. 96.

10. Jung, M.R.; Horgen, F.D.; Orski, S.V.; Rodriguez, V.; Beers, K.L.; Balazs, G.H.; Lynch, J.M. Validation of ATR FT-IR to identify polymers of plastic marine debris, including those ingested by marine organisms. Mar. Pollut. Bull. 2018, 127, 704-716. [CrossRef] [PubMed]

11. Tziourrou, P.; Kordella, S.; Ardali, Y.; Papatheodorou, G.; Karapanagioti, H.K. Microplastics formation based on degradation characteristics of beached plastic bags. Mar. Pollut. Bull. 2021, 169, 112470. [CrossRef] [PubMed]

12. Iannilli, V.; Di Gennaro, A.; Lecce, F.; Sighicelli, M.; Falconieri, M.; Pietrelli, L.; Battisti, C. Microplastics in Talitrus saltator (Crustacea, Amphipoda): New evidence of ingestion from natural contexts. Environ. Sci. Pollut. Res. 2018, 25, 28725-28729. [CrossRef] [PubMed]

13. Fotopoulou, K.; Karapanagioti, H.K. Surface properties of beached plastics. Environ. Sci. Pollut. Res. 2015, 22, 11022-11032.

14. Gniadek, M.; Dabrowska, A. The marine nano-and microplastics characterisation by SEM-EDX: The potential of the method in comparison with various physical and chemical approaches. Mar. Pollut. Bull. 2019, 148, 210-216. [CrossRef] [PubMed]

15. Steinmetz, Z.; Wollmann, C.; Schaefer, M.; Buchmann, C.; David, J.; Tröger, J.; Schaumann, G.E. Plastic mulching in agriculture. Trading short-term agronomic benefits for long-term soil degradation? Sci. Total Environ. 2016, 550, 690-705. [PubMed]

16. Feng, S.; Lu, H.; Liu, Y. The occurrence of microplastics in farmland and grassland soils in the Qinghai-Tibet plateau: Different land use and mulching time in facility agriculture. Environ. Pollut. 2021, 279, 116939. [CrossRef] [PubMed]

17. Ng, E.L.; Lwanga, E.H.; Eldridge, S.M.; Johnston, P.; Hu, H.W.; Geissen, V.; Chen, D. An overview of microplastic and nanoplastic pollution in agroecosystems. Sci. Total Environ. 2018, 627, 1377-1388. [CrossRef] [PubMed]

18. Kasirajan, S.; Ngouajio, M. Polyethylene and biodegradable mulches for agricultural applications: A review. Agron. Sustain. Dev. 2012, 32, 501-529. [CrossRef]

19. Yan, C.; He, W.; Mei, X. Agricultural Application of Plastic Film and Its Residue Pollution Prevention; Science Press: Beijing, China, 2010; pp. 76-86.

20. Liu, M.; Lu, S.; Song, Y.; Lei, L.; Hu, J.; Lv, W.; Zhou, W.; Cao, C.; Shi, H.; Yang, X.; et al. Microplastic and mesoplastic pollution in farmland soils in suburbs of Shanghai, China. Environ. Pollut. 2018, 242, 855-862. [CrossRef]

21. Zhang, S.; Yang, X.; Gertsen, H.; Peters, P.; Salanki, T.; Geissen, V. A simple method for the extraction and identification of light density microplastics from soil. Sci. Total Environ. 2018, 616, 1056-1065. [CrossRef] [PubMed] 